\title{
Cultural reproduction or cultural mobility? Unequal education achievement among Chinese college students
}

\author{
Bin Zhu(D)
}

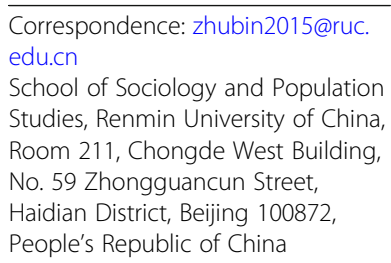

Correspondence: zhubin2015@ruc. edu.cn

School of Sociology and Population Studies, Renmin University of China, Room 211, Chongde West Building, No. 59 Zhongguancun Street, Haidian District, Beijing 100872, People's Republic of China

\begin{abstract}
This article investigates the influence of family class background on college students' education achievement by using the Beijing College Students Panel Survey. Statistical analyses show that elite class offspring are more likely to form student cadres and have higher English proficiency but lower grades. One reason for lower grades is that they do not devote enough time and energy to school. Another reason, however, is that the effect of cultural capital is weakened in a subjective, standardized system of examination and evaluation. Moreover, cultural capital has a greater effect when combined with other resources, meaning that elite-class children benefit more from cultural capital, which is consistent with the cultural reproduction theory.
\end{abstract}

Keywords: Cultural reproduction, Cultural resistance, Cultural mobility, Education achievement, Education inequality

\section{Research question}

In modern society, education has gradually become an important and decisive factor, influencing a person's ability to attain socioeconomic status. Therefore, inequality in educational opportunity has attracted wide attention from the broader society. The field of Chinese sociology has published numerous empirical findings, primarily focusing on the relationship between education expansion and inequality in educational opportunity. Modernization theory maintains that expanding education provides more educational opportunities for marginalized social groups and decreases inequality in educational opportunity (Boudon 1974). However, opponents, who adhere to the "MMI hypothesis" (Maximum Maintained Inequality) and the "EMI hypothesis" (Effectively Maintained Inequality), emphasize that education inequality is embedded in socio-structural inequality. These researchers argue that education inequality has little to do with education expansion, and as long as socio-structural inequality is perpetuated, education expansion alone cannot reduce inequality in educational opportunity (Raftery and Hout 1993; Lucas 2001; Breen and Jonsson 2005; Pfeffer 2008; Breen et al. 2009).

Empirical research in China generally supports both the MMI and EMI hypotheses; they have found that education expansion does not effectively eliminate inequality in

(c) The Author(s). 2020 Open Access This article is licensed under a Creative Commons Attribution 4.0 International License, which permits use, sharing, adaptation, distribution and reproduction in any medium or format, as long as you give appropriate credit to the original author(s) and the source, provide a link to the Creative Commons licence, and indicate if changes were made. The images or other third party material in this article are included in the article's Creative Commons licence, unless indicated otherwise in a credit line to the material. If material is not included in the article's Creative Commons licence and your intended use is not permitted by statutory regulation or exceeds the permitted use, you will need to obtain permission directly from the copyright holder. To view a copy of this licence, visit http://creativecommons.org/licenses/by/4.0/. 
educational opportunity (Liu 2006; Li 2006; Hao 2007; Wu 2009, 2016; Li 2010, 2014a; Wu 2013; Tang 2015; Ye and Ding 2015). One puzzle, however, is that educational opportunity inequality has not increased in response to the rapid increase of sociostructural inequality since the 1990s. At least, inequality in educational opportunity based on family class background has remained relatively stable. If inequality in educational opportunity is embedded in socio-structural inequality and is not correlated with education expansion, we need to ask: Why has inequality in educational opportunity based on family class background remained stable, instead of increasing in response to growing socio-structural inequality?

While education expansion does not eliminate inequality in educational opportunity, against the backdrop of ever-growing college enrollment, the number of college undergraduates increase each year, leading to devaluation of the bachelor's degree. As a result, increasing number of undergraduates chooses graduate education to improve their competency in the labor market. As competition to enter graduate school intensifies, students may use various resources to gain a competitive edge for admission. Family class background could play an increasingly important role in this regard. However, a recent study (Li 2016) finds that family class background has no significant influence on Chinese graduate school admission.

To understand these observations, we examine factors that not only expand inequality in educational opportunity but also those that suppress it. On one hand, we could focus our research on the macro-level, studying education policies and social institutions. On the other hand, we also need a micro-level understanding of how inequality in educational opportunity is formed in school, i.e., how family class background influences children's education achievement. On the micro-level that examines family class background, the existing research points to two mechanisms-resource transmission and cultural reproduction-influencing education attainment (Li 2006). Resource transmission is the mechanism by which a family transforms its socioeconomic status into advantages for child education. However, the cultural reproduction mechanism, which has received increasing attention, perceives cultural capital as the mediating variable that bridges socio-structural inequality and inequality in educational opportunity. Children of the elite class inherit more cultural capital and therefore have greater education achievement (Bourdieu and Passeron 2002b; Bourdieu 2004).

The cultural reproduction theory has been challenged by other theories, namely, the cultural resistance theory and the cultural mobility theory. The cultural resistance theory criticizes the cultural reproduction theory for overtly emphasizing the determinacy of social structure and overlooking the agency and cultural creativity of students and their families. In fact, students, especially working-class children, tend to resist their schools' paradigms and authority (Giroux 1983; Willis 2013). The cultural mobility theory argues that it takes a great amount of time to learn cultural capital and therefore, although family environment has bearing on early learning, it is not determinant. Subsequent socialization, especially school socialization, is also highly important. The children of non-elite families not only can acquire cultural capital in schools but can also benefit more from cultural capital than the children of elite families (DiMaggio 1982; Aschaffenburg and Maas 1997).

Although these two theories facilitate our understanding of inequality in educational opportunity, they have their own problems. First, cultural resistance theory emphasizes 
a negative type of agency, such as the agency working-class children employ when they challenge the school paradigm and its authority. Emphasizing negative agency means that their positive agency is often overlooked. Second, while cultural mobility theory refuses to see cultural capital as the medium of class reproduction, it agrees with cultural reproduction theory's basic assumption-cultural capital has a positive effect on education achievement. This assumption itself is debatable, as the effect of cultural capital is conditional rather than universal.

In sum, the three cultural theories mentioned above are insufficient for understanding class difference in education attainment. This article argues that the reproduction of education inequality is not as straightforward as the cultural reproduction theory suggests. Because the effect of cultural capital is not universal but conditional, lowerclass students have opportunities to assert some positive agency in schools, and so they can break through socio-structural barriers and ultimately, attain upward mobility. This process may be an internal, micro-level mechanism that keeps China's inequality in educational opportunity rather stable.

This article tests the above argument by analyzing class differences in college students' education achievement. Many studies have shown that college students' education achievement can affect their future employment and further education (Zhang and Cheng 2009; H. Li et al. 2012; Lai et al. 2012; Yue and Zhang 2014; Li 2016). However, empirical research on how college students acquire such education achievement is scattered. A few studies have observed class difference in student activity participation (Li et al. 2006; Zhu et al. 2013), but most of these studies simply apply the cultural reproduction theory without examining student agency and the working mechanism of cultural capital.

The remainder of this article is structured as follows: the three cultural theories are first compared. Based on comparisons among them, research hypotheses are derived. Data and methods are then described, and finally, statistical results are presented and analyzed.

\section{Theoretical comparison: cultural reproduction, cultural resistance, and cultural mobility}

Bourdieu proposes the cultural reproduction theory to explain social reproduction. The basic logic is as follows: elite-class children inherit more cultural capital from their families than children from other class backgrounds which, in turn, helps them obtain higher education achievement (Bourdieu and Passeron 2002a, 2002b; Bourdieu 2004). First, Bourdieu conceptualizes cultural capital as a third type of capital, different from economic capital or social capital. It consists of three forms: embodied cultural capital, objectified cultural capital, and institutional cultural capital (Bourdieu 1986). Bourdieu does not, however, precisely define cultural capital. Scholars believe that Bourdieusian cultural capital is essentially institutionalized elite culture that includes a specific way of talking, manners, habits, social networking, etc. (Lamont and Lareau 1988). In empirical studies, cultural capital is often measured by objects, knowledge, and behavior associated with elite high culture (Lareau and Weininger 2003; Jæger 2011).

Second, Bourdieu argues that family is the primary place where children acquire cultural capital, i.e., parents pass it onto their children through talking and behavior. Eliteclass children inherit more cultural capital because (1) elite-class parents have more cultural capital and are more capable of teaching it to their children; (2) elite families 
have greater socioeconomic capital to support children to acquire cultural capital such as art and music; and (3) elite-class parents have more free time available with their children to transmit cultural capital (Blasko 2003; Jæger 2011).

Finally, the positive effect of cultural capital on education achievement is derived from two aspects. First, school education is essentially "symbolic violence," as teachers-agents of the elite-evaluate students based on elite cultural standards. Second, this culture is monopolized by the elite but is not directly taught to students in schools. As a result, only students from elite families can master and perform elite cultural capital in daily activities and teacher-student communication, which means they obtain better teacher evaluations (Bourdieu and Passeron 2002a; Lareau 2015).

A series of studies done by Bourdieu and his collaborators have shown significant class differences in the likelihood of children entering college, as well as in the majors and progress of those who did enter college (Bourdieu and Passeron 2002b; Bourdieu 2004). Later empirical studies have found that college students from privileged families have higher grades and are more likely to participate in student cultural activities (Dumais 2002; Goldrick-Rab and Pfeffer 2009; Jæger 2011; Roksa and Potter 2011).

Although the cultural reproduction theory is supported by rich empirical studies, some researchers have challenged it. Among them, two theories have become influential - the cultural resistance theory and the cultural mobility theory. The cultural resistance theory criticizes the cultural reproduction theory for its overt emphasis on the determining effect of social structure exogenous to school and on reproduction endogenous to school. Furthermore, these emphases overlook the agency and creativity of actors in school and become rather fatalistic as it seems almost impossible to change existing inequality (Giroux 1983).

Willis's research reveals an "anti-school" culture among working-class children (whom he calls "folks"). This culture is primarily reflected in children's resistance against the school paradigm and its authority (Willis 2013:22). Willis argues that social relations and cultural forms in the "school paradigm" reflect the essence of capitalist society, and that resistance by "folks" is an innovative cultural reaction formed out of working-class culture (Willis 2013:68, 133-135). Ironically, working-class children's cultural resistance aids reproduction of the elite because those who accept the standard school paradigm are typically upwardly mobile. When "folks" resist the school paradigm, they give up the possibility of upward mobility and, in turn, reinforce the existing class structure.

The cultural mobility theory originates from DiMaggio's (1982; 1985) work. Inspired by Max Weber, DiMaggio argues that in a closed society in which different status groups rarely interact, cultural capital centered around elite culture is primarily learned in family contexts. In modern society, however, factors such as domestic and international market development, transportation and media expansion, urbanization, and educational expansion mean that social networks are no longer limited to small-scale status groups. People can acquire cultural capital from expanded social networks and social situations, among which school is an increasingly important place. Lower-class students can gradually learn cultural capital during the education process, which helps them acquire upward mobility (DiMaggio 1982; DiMaggio and Mohr 1985).

Another disparity between the cultural mobility theory and the cultural reproduction theory centers around which group of children benefit more from cultural capital. The 
cultural reproduction theory argues that elite-class children benefit more because their parents are usually more highly educated and have more knowledge about university operations and learning. These children, from observing and communicating with their parents, are better able to decode the "rules of the game" in schools. As a result, they can more effectively use cultural capital (Aschaffenburg and Maas 1997; Lareau 2015). However, some effects of cultural capital require the support of other types of capital (e.g., economic capital), and students cannot access other capital through individual effort. For example, in order to use cultural capital to obtain teacher and others' approval in social activities, students often need certain amount of economic capital to participate in these activities.

Cultural mobility theory, on the other hand, states that cultural capital and socioeconomic capital are interchangeable. Although elite families have advantages in both, transmitting cultural capital takes great time and energy, whereas imparting socioeconomic capital is rather simple. As a result, elite-class parents may emphasize socioeconomic capital but refrain from building a highly cultural family environment. The likely outcome is that elite-class children understand neither the operation nor the function of cultural capital (DiMaggio 1982; DiMaggio and Mohr 1985). In contrast, lower-class children can make efforts to acquire cultural capital in school, although it is more difficult for them to directly obtain socioeconomic capital. As a result, they focus more on appreciating cultural capital to catch up with elite-class children (DiMaggio 1982; Aschaffenburg and Maas 1997; De Graaf et al. 2000).

The cultural resistance theory and the cultural mobility theory are both in conversation with the cultural reproduction theory, but they have different emphases. While the cultural resistance theory maintains that schools eventually "reproduce," albeit in a different process, it stresses that the achieved outcome is a result of struggle. Distinctly, the cultural mobility theory believes that education is a channel for social mobility because workingclass children can acquire cultural capital from school and benefit more from it.

Both the cultural resistance theory and the cultural mobility theory extend our understanding of inequality in educational opportunity. However, there is room for further discussion. First, the agency and creativity of working-class children that the cultural resistance theory stresses are often reflected in empirical research as "antischool" culture. Some scholars assert that in fact, such culture is only present in very few working-class children, whereas mainstream working-class culture is not associated with the "anti-school" culture. Most working-class parents respect "intellectuals" and hope their kids will attain upward mobility through education (Blackledge and Hunter 1989:225-229). Therefore, this study moves the focus away from the negative agency: a minority of working-class children display to the positive agency most working-class children employ within the normal school paradigm.

Second, as previously stated, cultural capital helps students acquire higher education achievement because (1) teachers are agents of the elite class who test and evaluate students according to elite culture standards, and (2) schools do not explicitly teach elite culture as it is mainly acquired through socialization in the family (Bourdieu and Passeron 2002a; Lareau 2015). The cultural mobility theory disputes that elite culture is only learned at home, arguing that schools are not just a place for productivity but that cultural capital (i.e., elite culture) can also be learned there. However, the cultural mobility theory shares the basic assumption that teachers evaluate students using elite 
culture standards, and therefore, cultural capital has a positive effect on education achievement. But in our case, teachers may not be able to use cultural capital in evaluations when evaluations are objective or standardized.

In standardized evaluation, teachers have much less discretion in their assessment and must follow objective criteria ( $\mathrm{Hu}$ 2017). Objective evaluations emphasize how well students master evaluation content, which is more closely related to their own cognitive abilities and effort in school (Katsillis and Rubinson 1990; De Graaf et al. 2000; Sullivan 2001). Some scholars argue that cognitive ability and effort more closely align with the economic concept of human capital, which is universal and functional in nature, while cultural capital only reflects the special and social nature of elite identity and culture (Bourdieu 1986; Farkas 2003; Lareau and Weininger 2003).

To summarize, this paper argues that the function of cultural capital is affected by the objectivity and standardization of the evaluation system. The more objective and standardized the evaluation is, the weaker the effect of cultural capital is, and the more important the student's cognitive ability and effort are. Objective and standardized evaluations grant lower-class students room to assert agency, allow them to achieve higher education, and give them the ability to ultimately break through socio-structural constraints. As many studies have found, societies with a highly standardized educational system can usually suppress the influence of family class background in education, and thereby promote educational equality (Stevenson and Baker 1991; Park 2008; Horn 2009; Van de Werfhorst et al. 2010; Xu and Hampden-Thompson 2011; Byun et al. 2012; Karabel 2014). Very limited research, however, discusses how this relationship between objective evaluations and class background is realized inside a school. For the remainder of this article, I use the case of Chinese higher education to demonstrate my argument.

\section{Research hypotheses}

The cultural resistance theory claims that working-class children are inclined to defy school authority through wearing outlandish outfits, smoking, drinking, and fighting (Willis 2013:22). The theory's opponents believe that only a few students engage in these behaviors. Both sides are supported by empirical findings in studies on rural Chinese migrant children. Some scholars find that these children embrace "anti-school" culture; Zhou (2011) states, "Most children here do not care about studying, nor do they attempt to improve their grades. To the contrary, they refuse knowledge taught in school, and entertain by internet surfing, reading novels, and playing with each other." Other research, however, shows that migrant children who confronted with socio-structural limitations do not simply give up on school. On the contrary, these students instead work harder or choose a better opportunity for higher education (Xiong and Liu 2014). The abovementioned studies are all single-case studies that do not show a complete picture of education attainment in China. For centuries, Chinese believe that education leads to the highest honor and prestige. This popular belief has penetrated the Chinese society to the extent that some research has found little difference in educational beliefs between middle-class and lower-class parents (Hong and Zhao 2014). As such, there is no reason to believe that working-class children are more likely to exhibit "anti-school" culture or behavior. In contrast, considering the disadvantaged position their families hold in social class status, they have a stronger desire to move upward, which means they will likely work harder. Reflecting on these characteristics of working-class students, we arrive at Hypothesis 1 (Table 3). 
Hypothesis 1: Students from working-class or farming families work harder in school. As aforementioned, factors that influence education achievement depend on the form of evaluation. Existing studies often use grades, student cadre, and English Level Four scores to measure education achievement ( $\mathrm{Li}$ et al. 2006; Lai et al. 2012; Zhu et al. 2013; Li 2016). Based on the author's experience studying and teaching in the university setting, undergraduate curriculum has two characteristics. First, there are many common courses, such as math, politics, and general studies. These courses often use national-universal texts and are evaluated using standardized tests. Second, major courses either use standardized tests or essay assignments to assess student knowledge. Even in humanities and social sciences, which are usually more subjectively graded, answers are still standardized because most questions are "concept explanation," "short answer," and "discussion." Essay assignments are subjective, but most of the time, the grades for essays do not differ significantly. Additionally, very few classes use essay assignments to assess students' performance; therefore, essay assignments do not significantly affect overall grades when they are assigned. Generally, the author believes that current evaluations used in universities are rather objective and standardized. Standardized exams are the primary form of evaluation, and exam content is explicitly taught in class. In this context, teachers evaluate students based on their exam performance. Teachers have limited discretion in assigning grades. Therefore, grades are mostly determined by a student's cognitive ability and study effort. Cultural capital is often not relevant.

In contrast to grades, the selection of student cadre has rather ambiguous standards. Not only does a student's social network, especially their relationship with teachers, matter, but their extracurricular activity performance is also important-even more so. Extracurricular activity involvement demonstrates a student's leadership, organization, and communication abilities, as well as other skills that are not easily observed. Schools normally do not teach such skills, in which cultural capital plays an important role. Previous research found that elite-class children are more likely to participate in various college student activities and are more likely to become the leaders (or cadres) of student organization. One critical factor is that elite-class parents emphasize personality development, psychological maturity, and social skills in their children from a young age. As a result, elite-class children can communicate with teachers more easily; they also have more familiarity and can better adapt to the form and content of college student activities (Dumais 2002; Stuber 2009; Lehmann 2012; Li et al 2006).

When we analyze English Level Four scores, we find on one hand that hardworking students can eventually adapt to this type of standardized test; however, on the other hand, language is the most emphasized element of cultural capital. Bernstein, for example, pointed out that language ability develops through "tacit learning" in daily life. Family is the initial context in which children develop language ability, and it is the most important (Wang 2009:272-276). Many elite-class parents speak English themselves and start teaching their children English from early childhood.

In sum, the author argues that individual study effort has a decisive effect on overall grades, whereas cultural capital has no significant effect. If working-class children work harder in school, they should have the same or higher grades than elite-class children do. In comparison, cultural capital impacts leadership and English language ability more positively than grades do, and elite-class children, therefore, have the advantage 
in both of these aspects. Hypothesis 2 shows the effect of individual effort and cultural capital on grades.

Hypothesis 2: Individual study effort has a decisive effect on student grades. Therefore, working-class and farmers' children have higher grades than elite-class children do. In contrast, in student leadership and English Level Four scores, cultural capital is more influential, and elite-class children have an advantage in both areas.

Furthermore, if cultural capital helps college students obtain leadership roles and increase their English language ability, who benefits more? Generally, the cultural reproduction theory believes that elite-class children know more about the "rules of the game" in school, have more socioeconomic capital, and therefore are more capable of utilizing their cultural capital. Overall, elite-class children likely benefit more from cultural capital. The cultural mobility theory, on the other hand, stresses that workingclass children are more willing to use their cultural capital, while elite-class children use socioeconomic capital more often given that it yields quick and direct rewards.

The related empirical studies demonstrate inconsistent results. DiMaggio's research first proposed the cultural mobility model, but he only found that it applies to male students from lower- or middle-class families, and the cultural reproduction theory more accurately explains women's education achievement (DiMaggio 1982). Subsequent research is split: some support the cultural mobility model (De Graaf et al. 2000), some find no class difference in the effect of cultural capital (Blasko 2003), and still others find different modes of operation for varying forms of cultural capital (Jæger 2011; Sun 2010).

Student activity and English language ability are both important for Chinese college students in their future career and education; studying abroad is an optimal mix of these two assets ( $Z$. Li 2016). Against the backdrop of higher education expansion, studying abroad is now a major way for degree holders to increase their degree's value (Xu et al. 2014), and in turn, it spurs the social reproduction of the elite. Hypothesis 3 summarizes these points and reflects on the fact that college students from elite families are both capable of using and willing to use their cultural capital to obtain higher leadership roles and better English language ability.

Hypothesis 3: Compared to working-class and farmers' children, elite-class children are more heavily influenced by family cultural capital.

\section{Research method}

Data

This article uses data from the Beijing College Students Panel Survey (BCSPS), which is conducted by the Center for Survey and Data at the Renmin University of China. ${ }^{1}$ The Beijing Municipal Commission of Education provided a database of college students in 2006 and 2008 cohorts to use as our sampling frame. The survey randomly sampled 5100 college students through multi-stage, probability proportional sampling (PPS). The survey started in 2009, and from 2010 to 2013, four consecutive surveys were conducted on the same sample. Information collected in the survey includes basic information, mental state, school grades, social activities, political participation, source of income, career perspective, outcome of graduation, behavior, and values. ${ }^{2}$ This article

\footnotetext{
${ }^{1}$ The author thanks Shizheng Feng, Weidong Wang, Ding Li, among others for their generous provision of the data.

${ }^{2}$ Please refer to the "Report on the Development of Chinese College Students" (Li, 2014a, b) for detailed survey information.
} 
uses data collected from the on-campus students, which includes two portions. For the 2006 cohort, the first and second waves are used; for the 2008 cohort, all four waves are used. After deleting observations with missing values from the sample, the final sample size used in the analysis is 4004 .

\section{Variables}

\section{Dependent variable: education achievement in school}

In this article, education achievement consists of three elements: grades, student leadership, and English Level Four scores.

Each wave of the survey asks the respondents to report their class size and current grade rankings. This study divides students into five academic categories-the top 20 percent are valued at 5 , and then the following 20 percent are valued at 4 . In the same way, the bottom 20 percent are given a value at 1 . Thus, a higher value indicates a higher grade. This study takes respondents' final-year grades, which are cumulative grades for the entire 4 years in college. If a respondent's final grade is missing, his or her junior-year (the third year in college) grade is used. Considering that students finish most classes in their junior year, their senior-year grades have little impact on the final grades.

Previous studies often focus on whether the student becomes a student leader. This focus does not reflect the complexity of student leadership experience. There is a student cadre system in Chinese universities that to some extent resembles the cadre system in the communist party. Different types and levels of student cadres exhibit significant differences in multiple aspects that influence their future education and career. For example, based on the author's observations, leaders in student associations receive far greater preference for the graduate school exam-and-tuition waiver than other types of student cadres do. The author categorizes student cadres into five groups based on his experience and the data gathered from communicating with students. Table 1 shows these five groups. Generally, college student cadres are selected and gradually promoted. The higher the level is, the smaller the number of leadership positions is. Therefore, this study uses the top position that a student has held to determine the student's leadership value.

English Level Four score is chosen as part of the dependent variable because most college students have taken this test. In some universities, passing English Level Four Test is mandatory for graduation. Distinct from the college English exams organized by each university, English Level Four Test is a standardized language assessment across Chinese universities; therefore, this score is directly comparable. The researcher does, however, note that though the college English exam score is part of the final grade, it carries little weight and cannot assess college students' language ability.

\section{Core independent variables}

Core independent variables in this study include family class background, family cultural capital, and level of study effort. The first and second waves of the survey ask respondents to report their parents' occupation. The first wave asks about the job their parents worked for the greatest amount of time, and the second wave asks for their parents' current job. This study uses the currently held, higher-level occupation between the two parents as 
Table 1 Student leadership levels and values

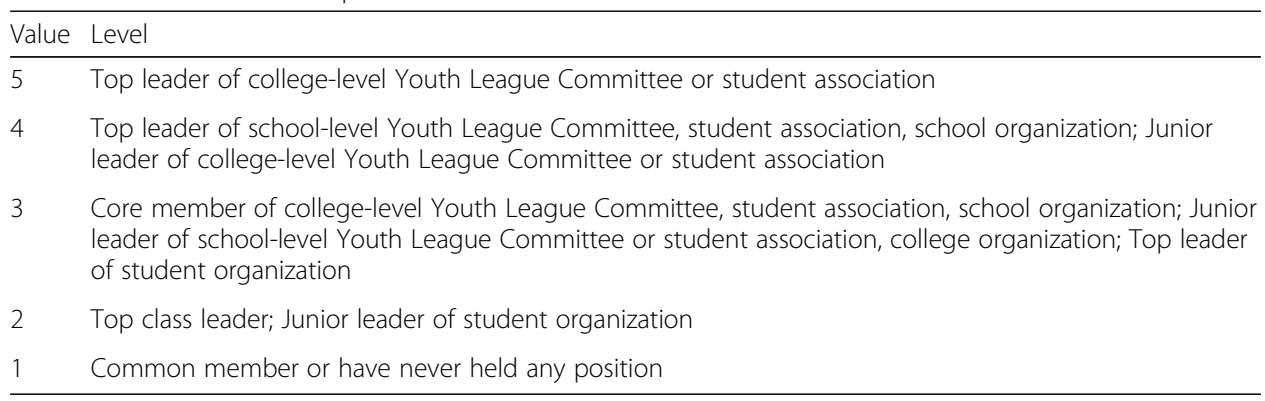

the family class background value. It takes the values from the second-wave survey. If parents' occupation is missing, that value in the first-wave survey is taken. Family class background consists of four categories: managerial class, including state-owned business managers, government officials, and private business owners; professional class; workingclass and farmers, including farmers, industrial workers, and the unemployed; and common nonphysical laborers (i.e., those working other occupations).

Connected with family class background is family cultural capital. Most empirical research in China uses parents' highest degree as the indicator of family cultural capital. However, as some scholars elucidate, elite-class parents do not necessarily provide a better cultural environment. To directly measure family cultural capital, this study uses family cultural resources as the indicator of family cultural capital. The first-wave survey asks respondents whether they have the following items at home: "newspaper subscription," "encyclopedia, dictionary, or other books of reference," "more than 50 books," "classic literature," "poem collection," and "art (such as painting)." If a student responds "yes," the variable is valued at 1 , and if a student answers "no," the variable is valued at 0 . Then, I create an index by adding up the values of the six items. The higher the score, the more the family cultural capital.

Variables used to measure study effort differ with varying education achievements. When examining school grades and English Level Four scores, the researcher uses class absence to measure student study effort. Each wave of the survey asks respondents to report the frequency of unexcused absences from both general education courses and major courses. The variable is valued at 3 for "often," 2 for "occasionally," and 1 for "never." The researcher uses the average score of the two waves of the survey. The higher the score, the more frequently the student skips classes. Student leadership is then measured by the amount of time a student spends on student activities. The survey asks respondents to report how much time on average they spend on student activities each week. The researcher uses the average of all college years as the concrete measurement.

\section{Control variables}

Considering the homogeneity of college students, the researcher only controls for variables in three aspects. The first aspect includes gender, ethnicity, and hukou prior to college. All three variables are dummy variables. The reference category for the gender variable is female, ethnicity is minority, and hukou is agricultural hukou.

The second group of control variables are school type, major, and year in school. The researcher categorizes schools into three groups. The first group, elite schools, includes 
Tsinghua University, Peking University, and Renmin University. These top three universities in Beijing were sampled separately in the survey. The second group includes all "211" universities ${ }^{3}$ except for the top three. The third group includes all non 211 universities. The major variable consists of three categories: humanities, social sciences, and natural sciences. Year in school is a dummy variable that uses the 2006 cohort as its reference category.

Finally, family economic capital is controlled. Even though family economic capital is not the focus of this study, because it acts as a resource transformation mechanism, it is essential in how family class background influences students' education achievement (Li 2006). This variable uses the log of family annual income reported in the first wave (2009). Table 2 shows the descriptive statistics of all variables.

\section{Models}

This article uses two models: The Ordered Logit (Ologit) model and the OLS model. The Ologit model is used when the dependent variable is an ordinal variable, e.g., school grades and student leadership. OLS is used when the dependent variable is a continuous variable.

\section{Result analyses}

\section{Family class background, cultural capital, and individual study effort}

According to the cultural reproduction theory and the cultural resistance theory, the first question this study needs to address is whether a class difference exists in students' cultural capital and level of study effort. The first model, model 1-1, uses family cultural capital as the dependent variable. Clearly, working-class and farming families have significantly less cultural capital than each of the three other classes and significantly less than elite families. This finding is consistent with the cultural reproduction theory. Model 1-2 examines college student absences. Controlling other variables shows that workingclass and farmers' children are much less likely to skip class than students from other social classes. Family economic capital has a significant and positive effect on skipping class, whereas the coefficient of cultural capital is not significant. Finally, as model 1-3 demonstrates, children of nonphysical and managerial classes spend less time in student activities than working-class and farmers' children do. The coefficient of the professional class is negative, but not significant. Additionally, family economic capital or cultural capital has no significant effect on the student activity participation of professional-class children. Therefore, although working-class and farmers' children have the least cultural capital, they work hardest in school, not only in terms of studying but also in terms of student activity participation. Such results support Hypothesis 1 (Table 3).

\section{Family class background and education achievement School grades}

As the baseline model, model 2-1 includes gender, ethnicity, hukou prior to college, university, major, year in school, and family class status. First, the results show that male students have significantly lower grades than female students do, and minority students have significantly lower grades than Han students do. Hukou prior to college has little impact on student grades. Second, neither university, major, nor year in school

${ }^{3}$ Two hundred and eleven universities refer to about 100 universities under the state's key construction, which were officially launched in November 1995 with the approval of the State Council. 
Table 2 Descriptive statistics of relevant variables $(N=4004)$

\begin{tabular}{|c|c|c|c|c|}
\hline \multicolumn{2}{|l|}{ Variable } & \multirow{2}{*}{$\frac{2006 \text { cohort }}{3.47(1.22)^{*}}$} & \multirow{2}{*}{$\frac{2008 \text { cohort }}{3.48(1.21)}$} & \multirow{2}{*}{$\frac{\text { All }}{3.48(1.21)}$} \\
\hline Educational achievement & School grades & & & \\
\hline & Student leadership & $2.01(1.02)$ & $2.25(1.17)$ & $2.12(1.10)$ \\
\hline & English Level Four score & $506.50(72.10)$ & $519.07(72.10)$ & $512.56(72.37)$ \\
\hline \multirow[t]{4}{*}{ Family background } & Working-class and farmers & 22.92 & 20.13 & 21.58 \\
\hline & Nonphysical laborer & 33.06 & 33.44 & 33.24 \\
\hline & Professional & 10.42 & 12.01 & 11.19 \\
\hline & Managerial class & 33.59 & 34.42 & 33.99 \\
\hline \multicolumn{2}{|l|}{ Family cultural capital } & $3.82(2.04)$ & $4.08(1.98)$ & $3.95(2.02)$ \\
\hline \multicolumn{2}{|l|}{ Family economic capital } & $10.58(1.14)$ & $10.61(1.11)$ & $10.60(1.13)$ \\
\hline \multicolumn{2}{|l|}{ Absence } & $1.99(0.48)$ & $1.96(0.48)$ & $1.97(0.48)$ \\
\hline \multicolumn{2}{|c|}{ Time spent on student activities (h) } & $4.67(6.55)$ & $4.48(4.62)$ & $4.58(5.0)$ \\
\hline \multicolumn{2}{|l|}{ Gender (1 = male, \%) } & 52.8 & 53.16 & 52.97 \\
\hline \multicolumn{2}{|l|}{ Ethnicity (1 = Han, \%) } & 89.29 & 89.18 & 89.24 \\
\hline \multicolumn{2}{|c|}{ Hukou before college (1 = nonagricultural, \%) } & 71.67 & 72.26 & 71.95 \\
\hline \multirow[t]{3}{*}{ University (\%) } & Elite university & 27.32 & 30.28 & 28.75 \\
\hline & 211 university & 35.52 & 35.66 & 35.59 \\
\hline & Non-211 university & 37.16 & 34.06 & 35.66 \\
\hline \multirow[t]{3}{*}{ Major (\%) } & Humanities & 9.46 & 11.96 & 10.66 \\
\hline & Social science & 33.88 & 33.23 & 33.57 \\
\hline & Natural science & 56.66 & 54.81 & 55.77 \\
\hline
\end{tabular}

*The standard deviation is listed in parentheses

have a significant effect; since each university gives school grades, no significant differences should exist in samples from each university, each major, or each cohort. Third, after controlling for the aforementioned variables, the researcher finds that family class background does significantly affect school grades. However, in contrast to what the cultural reproduction theory predicts, working-class and farmers' students have the highest grades.

In model 2-2, two variables are added-family economic capital and cultural capital. The results show that while economic capital has a significantly negative effect on grades, family cultural capital has no significant effect. After adding these two variables, the effect of family class background decreased dramatically. This result shows that family economic capital mediates the effect of family class background.

Finally, model 2-3 includes the "absence" variable. The more classes a student misses, the lower his or her grade. After controlling for this variable, neither family class nor family economic capital has a significant effect on grades. This result suggests that working-class and farmers' children have higher grades is because they devote time and energy to studying, while elite-class children use their time and energy elsewhere.

\section{Student leadership}

Model 3-1 only includes control variables and the family class status variable. Model 31 shows that male students hold more lower-level leadership positions on average than female students do. This aspect, along with the female advantage in grades found in 
Table 3 Relationships among family class background, cultural capital, and individual effort

\begin{tabular}{|c|c|c|c|}
\hline & $\begin{array}{l}\text { Family cultural } \\
\text { capital }\end{array}$ & Absence & $\begin{array}{l}\text { Time spent on student } \\
\text { activities }\end{array}$ \\
\hline & Model 1-1 & Model 1-2 & Model 1-3 \\
\hline & B/S.E. & B/S.E. & B/S.E. \\
\hline Gender $($ male $=1)$ & $-.250^{* * *}(.052)$ & $\begin{array}{l}.165^{* * *} \\
(.016)\end{array}$ & $.513^{*}(.203)$ \\
\hline Ethnicity $(\operatorname{Han}=1)$ & $.208^{* *}(.076)$ & $.030(.023)$ & $-.638^{*}(.260)$ \\
\hline Hukou (nonagricultural = 1) & $.992^{* * *}(.066)$ & $.006(.021)$ & $-.387(.260)$ \\
\hline \multicolumn{4}{|c|}{ University (reference: elite university) } \\
\hline 211 university & $-.072(.091)$ & $-.006(.028)$ & $-.249(.351)$ \\
\hline non-211 university & $-.161+(.090)$ & $-.022(.028)$ & $-.403(.350)$ \\
\hline \multicolumn{4}{|l|}{ Major (reference: humanities) } \\
\hline Social science & $-.224^{*}(.088)$ & $\begin{array}{l}-.078^{* *} \\
(.027)\end{array}$ & $-.217(.339)$ \\
\hline Natural science & $-.285^{* * *}(.085)$ & $-.016(.026)$ & $-.926^{* *}(.328)$ \\
\hline Cohort $(2008$ cohort $=1)$ & $.226^{* * *}(.048)$ & $-.022(.015)$ & $-.340+(.187)$ \\
\hline \multicolumn{4}{|c|}{$\begin{array}{l}\text { Family class (reference: working-class and } \\
\text { farmers) }\end{array}$} \\
\hline Nonphysical laborer & $.863^{* * *}(.073)$ & $\begin{array}{l}.097^{* * *} \\
(.023)\end{array}$ & $-.701 *(.287)$ \\
\hline Professional & $1.521^{* * *}(.107)$ & $\begin{array}{l}.153^{* * *} \\
(.033)\end{array}$ & $-.414(.422)$ \\
\hline Managerial class & $1.586^{* * *}(.087)$ & $\begin{array}{l}.107^{* * *} \\
(.028)\end{array}$ & $-.957^{* *}(.350)$ \\
\hline Family economic capital & $.447^{* * *}(.026)$ & $\begin{array}{l}.049^{* * *} \\
(.008)\end{array}$ & $-.050(.106)$ \\
\hline Family cultural capital & & $-.003(.005)$ & $.039(.061)$ \\
\hline _const. & $-2.339^{* * *}$ & $1.248^{* * *}$ & $7.065^{* * *}$ \\
\hline $\mathrm{N}$ & 4004 & 4004 & 4004 \\
\hline$R \wedge 2$ & .442 & .061 & .020 \\
\hline
\end{tabular}

$+p<0.1,{ }^{*} p<0.05,{ }^{* *} p<0.01,{ }^{* * *} p<0.001$

model 2-1, shows that gender inequality in Chinese universities has been largely reduced. Therefore, gender inequality in the labor market is likely the result of discrimination against women rather than a difference in men and women's human capital. The coefficients of ethnicity and hukou are both insignificant.

An interesting finding is that students in different universities and different cohorts show different patterns in taking leadership positions. The average leadership score of elite university students is the highest. The 2008 cohort on average scores is higher than the 2006 cohort. Such a distinction could be the outcome of different opportunity structures in different schools or cohorts. Better schools may have more organizations and thus more available leadership positions to fulfill. The 2008 cohort may also have more opportunities (Table 4).

Family class background has a significant and positive effect on leadership. Students from the elite class, especially the managerial class, have a considerable advantage over working-class and farming family students. To reveal the concrete mechanism of this effect, model 3-2 includes family economic capital and cultural capital. Family cultural capital may help students become student leaders, but the positive effect of economic capital is insignificant. 
Last, the researcher turns to the relationship between time spent on student activities and student leadership. Model 3-3 displays that time spent on activities has a significant and positive effect, i.e., the more a student participates in activities, the more likely he or she is to become a student leader. It may also work the other direction, i.e., student leaders spend more time in activities. If this statement is true, elite-class children, who are more likely to become student leaders, should spend more time in student activities, but model 1-3 rejects the explanation. The effect of family cultural capital remains significant after time spent on activities is added. Model 3-2 shows that the effect of family class background increases. Both models directly reveal that elite-class children spend less time on student activities than working-class and farmers' children do. Thus, although working-class and farmers' children participate more actively, they face difficulty competing for leadership positions because of their lack of cultural capital.

\section{English Level Four scores}

Ceteris paribus, the average English Level Four score of male students is 22 points lower than that of female students, showing again that male students fall behind female students. Han students have significantly higher scores than minority students do. Hukou prior to college has no significant effect. Moreover, students in elite schools, the 2008 cohort, or who major in social sciences or natural sciences have higher English Level Four scores. English is part of the University Entrance Exam. Students who gain admission into highly ranked universities normally have high English language ability. Humanity majors, on the other hand, have lower admission scores, and therefore, these students tend to have lower English language ability. Family class background has a significant and positive effect on English Level Four scores. Elite-class children, especially children of professionals, have considerably higher English Four scores. In model 4-2, the researcher adds family economic capital and cultural capital. Both have significant effects on English Level Four scores. The coefficient of family class background changes quite a lot but remains significant, showing a close relationship between language ability and family class background. Finally, model 4-3 includes the "absence" variable. Its coefficient is negative and significant, showing that one can increase their English language ability by working hard. Simultaneously, the effects of family class background and family economic capital become even greater, possibly because of the negative relationship between these variables and "absence" variable.

In sum, the effect of cultural capital differs significantly on different aspects of education achievement. It has little effect on college students' grades which are more associated with individual study effort. Elite-class children spend less time and energy studying, and therefore, have lower grades. In comparison, cultural capital has a significant positive effect on both student leadership and English language ability. Although elite-class children put in less effort on these two aspects, their advantage in cultural capital helps them obtain higher student leadership positions and better English Level Four scores. These results support Hypothesis 2.

\section{Class difference and the effect of cultural capital}

Based on the above analysis, family cultural capital has no influence on school grades, but it does significantly influence student leadership and English Level Four scores. 


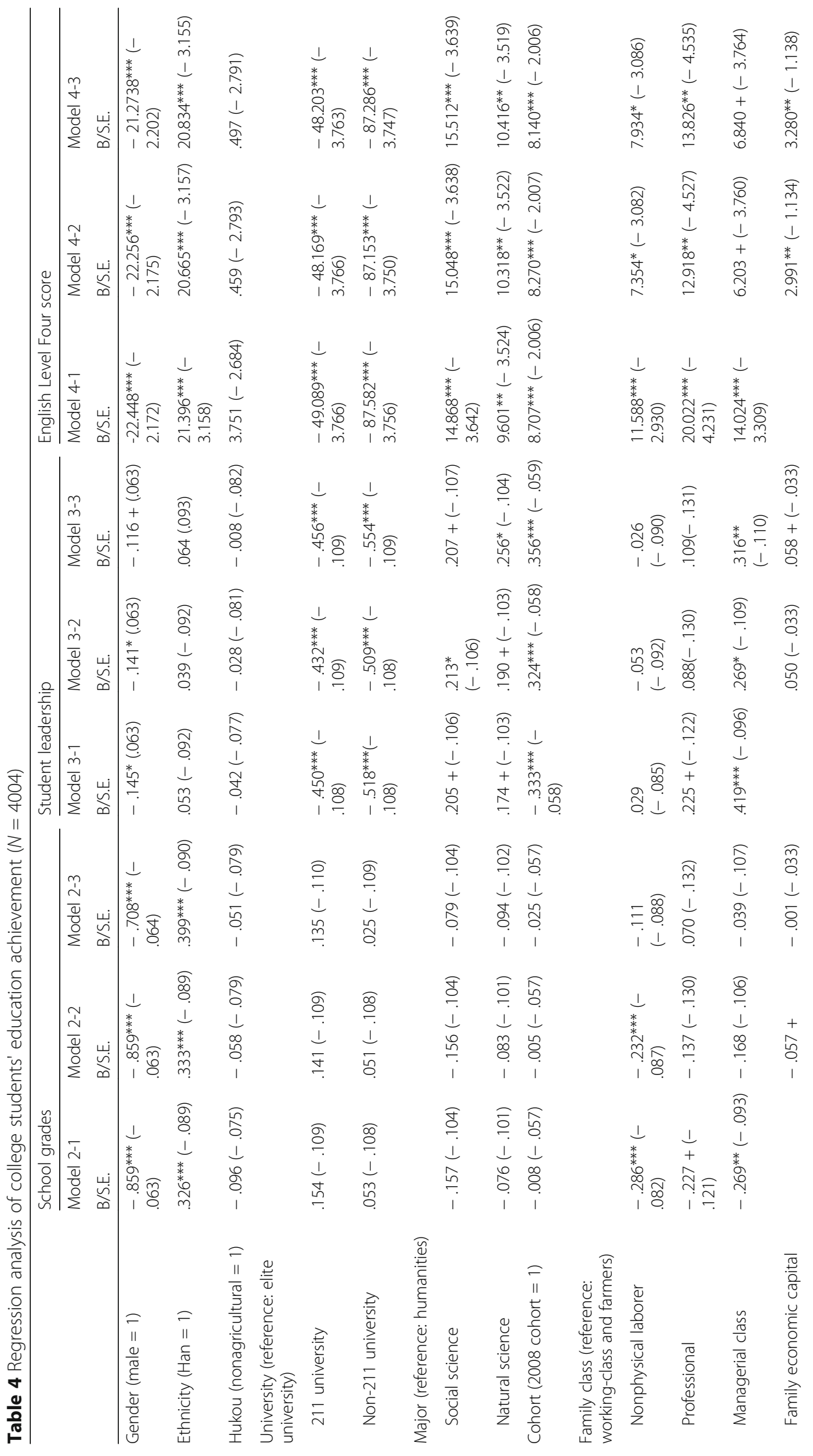




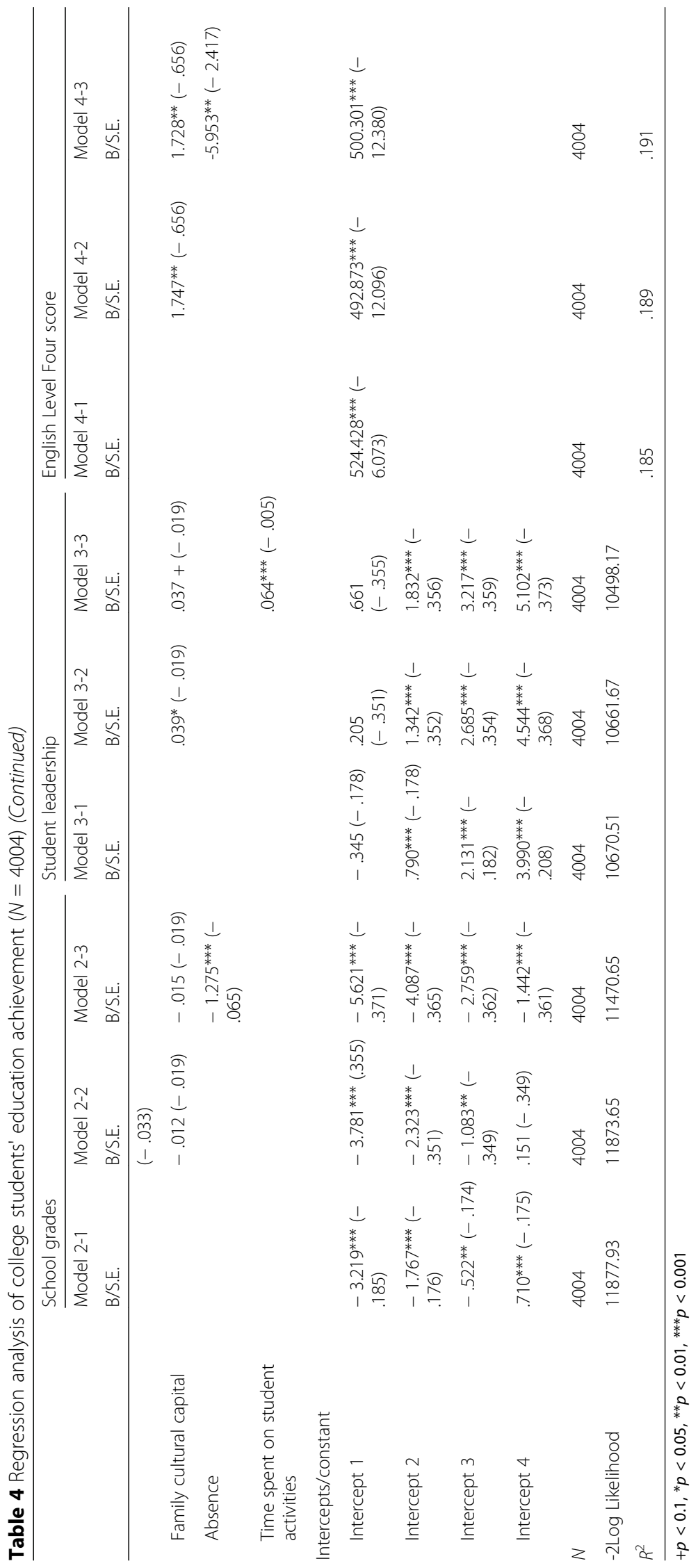


This observation leads to a further question: who benefits most from cultural capital? Based on models 3-3 and 4-3, the researcher has included the interaction between cultural capital and family class background. model 5-1 shows that, for student leadership, all the interaction terms have positive coefficients, but only the interaction for managerial class is significant. It suggests that cultural capital is more effective for children of the managerial class. For English Level Four scores (model 5-2), cultural capital is more effective for nonphysical and managerial classes. In general, these results support Hypothesis 3 as well as the cultural reproduction theory. The theory predicts that elite children benefit more from cultural capital because the conditions that strengthen the effect of cultural capital exist in elite families (Table 5).

\section{Conclusion and discussion}

To summarize our analytical results, family class background has a rather complicated effect on college students' education achievement. Elite-class children are more likely to become higher-level student leaders and have higher English Level Four scores. However, family class background has a negative effect on college students' school grades; in fact, students from the working-class and farmers' children have the best grades of all social classes. On the one hand, this finding is observed because working-class and farmers' children place more study effort than elite-class children to break through socio-structural barriers, whereas elite-class children have family economic capital as a resource.

On the other hand, and more importantly, the effect of family cultural capital is conditional. An objective exam and evaluation system use standardized tests to determine student grades. Cultural capital has little effect when an objective system is used. In this condition, individual study effort is the primary determining factor for grades. In contrast, teacher's discretion greatly influences non-standardized (i.e., subjective) assessment of student leadership; cultural capital has great importance in this regard. Even if students from working-class and farming families work hard, they cannot compete with elite-class children successfully.

Further analyses show that elite-class children benefit most from the cultural capital. Cultural capital is more effective in helping students from the managerial class which gain higher-level student leadership positions and higher English Level Four scores. There are two potential reasons for this effect. First, cultural capital is the most effective when combined with such factors as economic capital and information decoding ability. Elite families have advantage in all these aspects. Second, student leadership experience and English Level Four scores are important for elite-class children's future development, especially for those who plan to study abroad to further their education. They are, therefore, more willing to enlist cultural capital to get ahead in these areas.

Statistical results are consistent with the three hypotheses, but they challenge the existing cultural theories. First, the cultural reproduction theory assumes that cultural capital helps students obtain education achievement. This study shows, however, that the effect of cultural capital is not unconditional but rather constrained by the specificities of the exam and evaluation system. Second, the cultural resistance theory stresses the negative agency working-class children hold as they resist the school paradigm, but it overlooks the positive effort most students exhibit. Education achievement in college is often the combined result of cultural capital and individual study effort. Cultural capital has limited effect on grades, whereas individual effort has a decisive effect. Cultural 
Table 5 Class difference in the effect of cultural capital

\begin{tabular}{|c|c|c|}
\hline & Model 5-1 & Model 5-2 \\
\hline & B/S.E. & B/S.E. \\
\hline Gender $($ male $=1)$ & $-.111+(.063)$ & $-21.166^{* * *}(2.203)$ \\
\hline Ethnicity $(\operatorname{Han}=1)$ & $.061(.093)$ & $20.784^{* * *}(3.155)$ \\
\hline Hukou (nonagricultural = 1) & $.019(.083)$ & $.517(2.801)$ \\
\hline \multicolumn{3}{|l|}{ University (reference: elite university) } \\
\hline 211 university & $-.457^{* * *}(.109)$ & $-48.211^{* * *}(3.762)$ \\
\hline Non-211 university & $-.539^{* * *}(.109)$ & $-86.949^{* * *}(3.753)$ \\
\hline \multicolumn{3}{|l|}{ Major (reference: humanities) } \\
\hline Social science & $.214^{*}(.107)$ & $15.661^{* * *}(3.638)$ \\
\hline Natural science & $.226^{*}(.104)$ & $10.668^{* *}(3.520)$ \\
\hline Cohort (2008 cohort = 1) & $.350^{* * *}(.059)$ & $8.139^{* * *}(2.011)$ \\
\hline \multicolumn{3}{|c|}{ Family class (reference: working-class and farmers) } \\
\hline Nonphysical laborer & $-.135(.144)$ & $-.044(4.947)$ \\
\hline Professional & $-.214(.373)$ & $14.179(12.569)$ \\
\hline Managerial class & $-.069(.223)$ & $-3.579(7.590)$ \\
\hline Family economic capital & $.054(.033)$ & $3.214^{* *}(1.139)$ \\
\hline Family cultural capital & $-.020(.035)$ & $-.649(1.216)$ \\
\hline \multicolumn{3}{|l|}{ Family class $\times$ cultural capital } \\
\hline Nonphysical laborer $\times$ cultural capital & $.056(.044)$ & $3.307^{*}(1.495)$ \\
\hline Professional $\times$ cultural capital & $.100(.078)$ & $1.398(2.658)$ \\
\hline Managerial class $\times$ cultural capital & $.112^{*}(.051)$ & $3.569 *(1.753)$ \\
\hline Time spent on student activities & $.064^{* * *}(.005)$ & \\
\hline Absence & & $-5.974^{* *}(2.147)$ \\
\hline _const. & & $505.187^{* * *}(12.546)$ \\
\hline Intercept 1 & $.529(.360)$ & \\
\hline Intercept 2 & $1.702^{* * *}(.361)$ & \\
\hline Intercept 3 & $3.089^{* * *}(.364)$ & \\
\hline Intercept 4 & $4.975^{* * *}(.378)$ & \\
\hline N & 4004 & 4004 \\
\hline$R^{2}$ & & .192 \\
\hline -2Log Likelihood & 10493.032 & \\
\hline
\end{tabular}

mobility happens to the extent that working-class children are more hardworking than elite-class children. Cultural capital has a considerable effect on student leadership and English language ability; therefore, individual effort can only diminish but not suppress family class inequality. Finally, distinct from the cultural mobility theory, the effects of cultural capital and other socioeconomic capital are complementary, rather than substitutive. In areas where cultural capital is the most effective, the Matthew Effect is likely to exacerbate working-class children's difficulties in achieving upward mobility.

In general, this paper emphasizes the need to include the positive agency of students and the complexity of cultural capital in the research on the social reproduction of cultural capital and educational attainment. For a more complete understanding of the mechanism by which inequality in educational opportunity forms, the current theoretical model of "family class background - cultural capital - education achievement" should be 
extended to "family class background - cultural capital/positive agency - education achievement." The extended model does not negate the inequality in education attainment, but it does not see it as structurally determined and unchangeable either.

Furthermore, these results provide a micro-level understanding of the two questions proposed at the beginning of this article. On the one hand, because working-class children study harder and have higher grades, they do not fall behind elite-class children in terms of entering graduate school. A recent study finds that universities provide a fair and open study environment and experience for students from various classes. Anyone can increase their human capital through university education, and students from underprivileged families gain more human capital (Xu 2017). On the other hand, the standardized evaluation of working-class children's study effort is not only present in universities, but throughout the entire educational process. Under the current Chinese education regime, standardized testing is the decisive path to higher education. Working-class children can always offset their shortcomings in cultural capital by putting in more individual effort, thereby breaking socio-structural barriers and ultimately, achieving upward mobility. As such, while socio-structural inequality has expanded in China, inequality in educational opportunity inequality has not increased as much as economic inequality does.

However, this article discusses only college students' education achievements. Whether the results hold for middle or primary school students remains untested in the panel data on middle and primary schools. Compared with college students, middle and primary school students differ in at least two aspects. First, school grades for middle and primary school students are more important, especially when applied to High School Entrance Exams and University Entrance Exams. Therefore, elite families focus more on grades. Second, most college students live in school dorms, whereas most middle and primary school students live with their parents at home. Because they are monitored by parents on a daily basis, it is unlikely that elite-class children in middle or primary school can spend as much time and energy on extracurricular activities. Therefore, it is possible that middle and primary school students from elite families may have better grades than their working-class classmates (Li and Qiu 2016). Even if this is the case, it is not at odds with the conclusion in this study. For the author's purpose, working-class children's hard work does not upend inequality in education opportunity, but suppresses its increase as socio-structural inequality becomes higher.

Additionally, the stable education inequality in China may result from other macro-level social policies and institutions. This article only proposes one possible micro-level explanation. Future research may discuss the effects of other structural factors at the macro-level.

Acknowledgements

This paper is adapted from one chapter of the author's doctoral dissertation. I thank my advisor, Professor Lulu Li for his continuous and careful mentorship. I want to also thank the anonymous reviewers for their valuable suggestions for improvement.

Author's contributions

I took all responsibility for this paper. The author(s) read and approved the final manuscript.

Funding

The author declares no founding support.

This paper uses data from the Beijing College Students Panel Survey (BCSPS), conducted by the Center for Survey and Data of the Renmin University of China. The author thanks Shizheng Feng, Weidong Wang, Ding Li, and others for their generous provision of the data. 


\section{Competing interests}

The author declares there is no competing interest.

Received: 20 March 2020 Accepted: 11 May 2020

Published online: 21 May 2020

\section{References}

Aschaffenburg, Karen, and Ineke Maas. 1997. Cultural and Educational Careers: The Dynamics of social reproduction. American Sociological Review 62 (4): 573-587.

Blackledge, David and Barry Hunter. 1989. Schools of Sociology of Education: Sociological Explanations on Education. Wang, Bo, Fangming Chen and Ping Hu trans. Beijing: Chunqiu Press.

Blasko, Zsuzsa. 2003. Cultural Reproduction or Cultural Mobility? Review of Sociology 9 (1): 5-26.

Boudon, Raymond. 1974. Education, opportunity, and social inequality: changing prospects in western society. New York: Wiley.

Bourdieu, Pierre. 1986. The Forms of Capital. In Handbook of Theory and Research for the Sociology of Education, ed. J. Richardson, 241-258. Westport: Greenwood.

Bourdieu, Pierre. 2004. The state nobility: elite schools in the field of power. Stanford University Press.

Bourdieu, Pierre, and Jean-Claude Passeron. 2002a. Reproduction in education, society and culture. 2nd ed. London; Newbury Park: Sage Publications.

Bourdieu, Pierre, and Jean-Claude Passeron. 2002b. The Inheritors: French students and their relations to culture. First ed. Chicago: Univ of Chicago Pr.

Breen, Richard, and Jan O. Jonsson. 2005. Inequality of Opportunity in Comparative Perspective: Recent Research on Educational Attainment and Social Mobility. Annual Review of Sociology 31: 223-243.

Breen, Richard, Ruud Luijkx, Walter Muller, and Reinhard Pollak. 2009. Nonpersistent Inequality in Educational Attainment: Evidence from Eight European Countries. American Journal of Sociology 114 (5): 1475-1521.

Byun, Soo-yong, Evan Schofer, and Kyung-keun Kim. 2012. Revisiting the Role of Cultural Capital in East Asian Educational Systems: The Case of South Korea. Sociology of Education 85 (3): 219-239.

de Werfhorst, Van, G. Herman, and J.B. Jonathan Mijs. 2010. Achievement Inequality and the Institutional Structure of Educational Systems: A Comparative Perspective. Annual Review of Sociology 36: 407-428.

DiMaggio, Paul. 1982. Cultural Capital and School Success: The Impact of Status Culture Participation on the Grades of US High School Students. American Sociological Review 47 (2): 189-201.

DiMaggio, Paul, and John Mohr. 1985. Cultural Capital, Educational Attainment, and Marital Selection. American Journal of Sociology 90 (6): 1231-1261.

Dumais, Susan A. 2002. Cultural Capital, Gender, and School Success: The Role of Habitus. Sociology of Education 75 (1): $44-$ 68.

Farkas, George. 2003. Cognitive Skills and Noncognitive Traits and Behaviors in Stratification Processes. Annual Review of Sociology 29: 541-562.

Giroux, Henry A. 1983. Theories of Reproduction and Resistance in the New Sociology of Education: A Critical Analysis. Harvard Educational Review 53 (3): 257-293.

Goldrick-Rab, Sara, and Fabian T. Pfeffer. 2009. Beyond Access: Explaining Socioeconomic Differences in College Transfer. Sociology of Education 82 (2): 101-125.

Graaf, De, Nan Dirk, Paul M. De Graaf, and Gerbert Kraaykamp. 2000. Parental Cultural Capital and Educational Attainment in the Netherlands: A Refinement of the Cultural Capital Perspective. Sociology of Education 73 (2): 92-111.

Hao, Dahai. 2007. Research on Stratification of Chinese Urban Education. Social Sciences in China 6: 94-108.

Hong, Yanbi, and Yandong Zhao. 2014. From Capital to Habitus: The Class Differentiation of Family Educational Pattern in Urban China. Sociological Studies 4: 73-93.

Horn, Daniel. 2009. Age of Selection Counts: A Cross-Country Analysis of Educational Institutions. Education Research and Evaluation 15 (4): 343-366

Hu, Anning. 2017. Cultural Capital Research: A Reevaluation under the Chinese Context. Social Science 1: 64-71.

Jæger, Mads Meier. 2011. Does Cultural Capital Really Affect Academic Achievement? New Evidence from Combined Sibling and Panel Data. Sociology of Education 84 (4): 281-298.

Karabel, Jerome. 2014. The Chosen: The Hidden History of Admission and Exclusion at Harvard, Yale, and Princeton. Xie, Ailei et al. translated. Beijing: Renmin University Press.

Katsillis, John, and Richard Rubinson. 1990. Cultural Capital, Student Achievement, and Educational Reproduction: The Case of Greece. American Sociological Review 55 (2): 270-279.

Lai, Desheng, Dahu Meng, and Su. Lifeng. 2012. Substitution or Complementation: A Study on Joint Mechanism of Human Capital and Social Capital to College Graduates' Employment. Peking University Education Review 1: 13-31.

Lamont, Michele, and Annette Lareau. 1988. Cultural Capital: Allusions, Gaps and Glissandos in Recent Theoretical Developments. Sociological Theory 6 (2): 153-168.

Lareau, Annette. 2015. Cultural Knowledge and Social Inequality. American Sociological Review 80 (1): 1-27.

Lareau, Annette, and Elliot B. Weininger. 2003. Cultural Capital in Educational Research: A Critical Assessment. Theory and Society 32 (5-6): 567-606.

Lehmann, Wolfgang. 2012. Extra-Credential Experiences and Social Closure: Working-Class Students at University. British Educational Research Journal 38 (2): 203-218.

Li, Chunling. 2010. Expansion of Higher Education and Inequality in Opportunity of Education: A study on effect of "Kuozhao" policy on equalization of educational attainment. Sociological Studies 3: 82-113.

Li, Chunling. 2014a. The Changing Trend of Educational Inequality in China(1940-2010):Reexamining the Urban-rural Gap on Educational Opportunity. Sociological Studies 2: 65-89.

Li, Fengliang, Longlong Hou, and Dongmao Wen. 2006. Effect of Parental Educational Background on Children's Study and Social Activity in College. Chinese Journal of Sociology 1: 112-129.

Li, Hongbin, Lingsheng Meng, Xinzheng Shi, and Wu. Binzhen. 2012. Parental Political Capital and Children's Labor Market Performance: Evidence from the First Job Offers of Chinese College Graduates. China Economic Quarterly 3: $1011-1026$. 
Li, Lulu. 2014b. Report on the development of Chinese college students (2014). Beijing: Renmin University Press.

Li, Yu. 2006. Institutional Change and Educational Inequality: Mechanism in Educational Stratification in Urban China: $1966-$ 2003. Social Sciences in China 6: 97-109.

Li, Zhonglu. 2016. Family Background, Academic Performance and Admission to Postgraduate Study in China. Chinese Journal of Sociology 3: 86-109.

Li, Zhonglu, and Zeqi Qiu. 2016. Family Background and Children's Academic Performance: Evidence from the compulsory education in China. Sociological Studies 4: 121-144.

Liu, Jingming. 2006. Higher Education Expansion and Educational Opportunity Inequality: 1978-2003. Chinese Journal of Sociology 3: 158-179.

Lucas, Samuel R. 2001. Effectively Maintained Inequality: Education Transitions, Track Mobility and Social Background Effects. American Journal of Sociology 106 (6): 1642-1690.

Park, Hyunjoon. 2008. The Varied Educational Effects of Parent-Child Communication: A Comparative Study of Fourteen Countries. Comparative Education Review 52 (2): 219-243.

Pfeffer, Fabian T. 2008. Persistent Inequality in Educational Attainment and its Institutional Context. European Sociological Review 24 (5): 543-565.

Raftery, Adrian E., and Michael Hout. 1993. Maximally Maintained Inequality: Expansion, Reform, and Opportunity in Irish Education, 1921-75. Sociology of Education 66 (1): 41-62.

Roksa, Josipa, and Daniel Potter. 2011. Parenting and Academic Achievement Intergenerational Transmission of Educational Advantage. Sociology of Education 84 (4): 299-321.

Stevenson, David L., and David P. Baker. 1991. State Control of the Curriculum and Classroom Instruction. Sociology of Education 64 (1): 1-10.

Stuber, Jenny M. 2009. Class, Culture, and Participation in the Collegiate Extra-Curriculum. Sociological Forum 24 (4): $877-900$.

Sullivan, Alice. 2001. Cultural Capital and Educational Attainment. Sociology 35 (4): 893-912.

Sun, Yuantai. 2010. Family Background, Cultural Capital and Educational Attainment: A Study on Shanghai Urban Residents. Youth Studies 2: 35-43.

Tang, Junchao. 2015. Lost at the Starting Line: A Reconsideration on Educational Inequality in China (1978-2008). Sociological Studies 3: $123-145$.

Wang, Ruixian. 2009. Bernstein: Introduction to Speech Code and Education. In Sociology of Education: Figures and Thoughts, ed. Renjie Zhang. Shanghai: East China Normal University Press.

Willis, Paul. 2013. Learning to labour: how working class kids get working class jobs. Shu Mi and Minhua Ling trans. Nanjing: Yilin Press.

Wu, Xiaogang. 2016. Higher Education, Elite Formation and Social Stratification in Contemporary China. Chinese Journal of Sociology 3: 1-31.

Wu, Xiaogang. 2009. Economic Transition, School Expansion, and Educational Inequality in China, 1990-2000. Chinese Journal of Sociology 5: 88-113.

Wu, Yuxiao. 2013. The Keypoint School System, Tracking, and Educational Stratification in China, 1978-2008. Sociological Studies 4: 179-202.

Xiong, Chunwen, and Huijuan Liu. 2014. The Process of Self-selection and Self-disqualification in an Institutional Context: A Case Study of Culture in Migrant Children Schools. Peking University Education Review 4: 54-77.

Xu, Duoduo. 2017. From Poverty to Prosperity: Poverty, Non-Cognitive Abilities, and First-Job Earnings. Chinese Journal of Sociology 4: 90-118.

Xu, Jiayun, Tinghua Liu, and Ping Li. 2014. Does Oversea Education Experience Raise Income? Economic Science 1: 90-101.

$\mathrm{Xu}$, Jun, and Gillian Hampden-Thompson. 2011. Cultural Reproduction, Cultural Mobility, Cultural Resources, or Trivial Effect? A Comparative Approach to Cultural Capital and Educational Performance. Comparative Education Review 56 (1): 98-124.

Ye, Xiaoyang, and Yanqing Ding. 2015. Expanding Chinese Higher Education: Quality and Social Stratification. Chinese Journal of Sociology 3: 193-220.

Yue, Changjun, and Kai Zhang. 2014. Research on Job-hunting Result and Starting Salary of College Graduates and Its Influential Factors. Educational Research 11: 72-83.

Zhang, Shun, and Cheng Cheng. 2009. An Empirical Study on Factors Causing the Difficulty of Job-seeking among Undergraduates in Western China: a Comparative Study among Social Capital, Human Capital, Material Capital and Their Interactive Effect. Youth Studies 2: 1-10.

Zhou, Xiao. 2011. Counter-school culture: a comparative study of "Lads" and "Zidi.". Chinese Journal of Sociology 5: 70-92.

Zhu, Xinzhuo, Junhua Shi, and Zhihui Dong. 2013. The Impact of Family Background on Occupying Student Union Cadres of University Students. Journal of Higher Education 4: 71-78.

\section{Publisher's Note}

Springer Nature remains neutral with regard to jurisdictional claims in published maps and institutional affiliations. 